Uludag Univ. J. Fac. Vet. Med. 24 (2005), 1-2-3-4: 105-110

\title{
Mikotoksinler ve Tanı Yöntemleri
}

\author{
H. Hüseyin ORUÇ*
}

Geliș Tarihi: 02.12.2005

Kabul Tarihi: 23.02.2006

\begin{abstract}
Özet: Küf üremesi ve mikotoksin oluşumu, ürün kompozisyonu, sıcaklık, nem, havalandırma, insektlerin verdiği zararlar ve küfün spor miktarı gibi faktörlerin etkileşimlerine bağlı olarak gıda, yem ve yem hammaddelerinde şekillenebilmektedir. Tarımsal ürünlerin dörtte biri ciddi boyutta mikotoksinlerle kontaminasyona uğrayabilmektedir. Mikotoksinler çeşit ve miktarlarına bağlı olarak kontamine gıda ve yemleri tüketen insan ve hayvanlarda sağlık problemleri oluşturabilmekte, ayrıca bu ürünlerin ihracatı da olumsuz etkilendiğinden büyük ekonomik kayıplara neden olabilmektedir. Bu nedenlerle, tarımsal ürünlerde mikotoksinlerin rutin kontrolleri için mikotoksinlerin öneminin ve tanı yöntemlerinin iyi bilinmesi gereklidir.
\end{abstract}

Anahtar Kelimeler: Mikotoksinler, gıda, yem, tanı yöntemleri.

\section{Mycotoxins and Diagnosis}

Summary: Depending upon the interactions of several factors such as substrate composition, temperature, water activity, oxygen tension, insect damage and spore concentration, the growth of the fungus and consequently production of mycotoxins may be occured in food, feed and feedstuffs. Nearly quarter of the agricultural products could be subjected to a serious contamination level with mycotoxins. The type and the contamination level of the toxin has important impact on the health of human and animals consuming contaminated products. Beside of their health problems, they may also constitute important economic lose notably during the exportation of agricultural products. Therefore, the importance and diagnosis techniques of mycotoxins should be well known in order to assure better control of mycotoxins in agricultural products.

Key Words: Mycotoxins, food, feed, diagnosis.

\section{Giriș}

Mikotoksin, küfler tarafindan oluşturulan ikincil toksik bileşiklere verilen genel isimdir. Mikotoksinler, gida ve yemlerde bulunan kimyasal etkenler içerisinde insan ve hayvan sağlığını tehdit eden en ciddi tehlikelerden biridir. Mikotoksin çeşitine göre yerel bir sorun olabilirken, dünyanın farklı coğrafyalarında yetiştirilen benzer ürünlerde ortaya çıkmasıyla daha çok genel bir sorun olabilmektedir. Tarımsal ürünlerde mikotoksin oluşumu, uygun koşullarda ürüne bağlı olmak üzere, hasattan tüketime kadar he- men her aşamada meydana gelebilmektedir. Mikotoksinler, gıda güvenliğinin sağlanması açısından kontrol altına alınması gereken önemli sorunlardan biridir. İnsan ve hayvan sağllğı aç1sından önemli olan findık, antep fistığı, kuru incir, siyah zeytin, kırmızı toz ve pul biber gibi ihraç ürünlerinin yanında, süt ve süt ürünleri ve başta mısır olmak üzere diğer tahıl ürünleri mikotoksinlerle kontamine olabilmektedir.

Bugün bilinen 300'den fazla mikotoksin olmasina rağmen, bunlardan beş veya altı tanesi çok önemlidir. Önem derecesine göre sıralama ülke ve bölgelere göre farklılık göstermekle bir-

Yard.Doç. Dr.; U. Ü. Vet. Fak. Farmakoloji ve Toksikoloji Anabilim Dalı. Bursa-Türkiye. 
likte aflatoksinler, okratoksin A (OTA), fumonisinler, trikotesenler ve zearalenonun birinci derecede önemli mikotoksinler olduğu konusunda araştırıcılar görüş birliğine varmışlardır ${ }^{2,22}$. Örneğin Amerika Birleşik Devletleri'nde (ABD), misırda fumonisin birinci derecede önemli mikotoksinler arasında değerlendirilirken, Avustralya'da mısır beslenmede fazla kullanılmadığından fumonisin varlığı önemli bir tehlike olarak görülmemektedir. Avrupa'da genel olarak sıcaklığının uygun olmaması nedeniyle yüksek düzeylerde aflatoksinler oluşmaması ve ithal ürünlerin sık1 denetlenmesi nedeniyle de tüketicilerin sağl1ğ1 için fazla tehdit oluşturmazken; ABD dahil olmak üzere Amerika, Afrika ve Asya kitalarındaki pek çok ülke ve Türkiye için önemini korumaktadır. OTA, Avrupa'da tahillarda yaygin olarak bulunabilmekte, bu nedenle un ve ekmekte OTA sik sık tespit edilebilmektedir. Yapılan kan ve süt analizleri tüketicilerin OTA'ya maruz kaldığııı göstermektedir ${ }^{15}$. Özellikle Balkanlarda Balkan Endemik Nefropati (BEN) olarak adland1rılan böbrek hastalığının OTA ve sitrinin içeren tahıl tüketimine bağlı olduğu kanıtlanmıştır ${ }^{23,34}$.

Mikotoksinlerle zehirlenme genellikle kronik nitelikte olurken, akut nitelikte de olabilmekte ve çok ciddi sonuçlarla karşılaşılabilmektedir. Örneğin Kenya'da 2004 yılı nisan ve haziran ayları arasinda, temel besin maddesi olarak kullanılan mısır ve misır ürünlerini yiyen insanlarda ortaya çıkan aflatoksikozis olayında, 317 zehirlenme olmuş ve bunlardan 125 'i ölümle sonuçlanmıştır. Tespit edilen aflatoksin miktarı mısırda 48.000 ppb'ye ulaşmıştır ${ }^{20}$.

$\mathrm{Bu}$ makalede önemli olan mikotoksinler, gıda ve yemlerin tüketim sıklı̆̆ 1 , temel gıda maddesi olma gibi özellikleri dikkate alınarak incelenecektir.

\section{Tahıl ve ürünleri}

Mikotoksin varlığı ile ilgili dünyada ilk çalışmalar tahıllar üzerinde yapılmıştır. Küflü mısirdan izole edilen Penicillium puberulum ekstraktının toksik olduğu 1913 yılında belirlenmiş ve bu zehirli maddeye penisillik asit adı verilmiştir ${ }^{24}$. Tahıl ve ürünleri temel gida maddesi olmaları ve yem maddesi olarak da yaygin olarak kullanılmaları, toksik küf gelişmesi ve mikotoksin oluşumu için hasat öncesinde, hasat sırasında ve sonrasinda da ciddi boyutta hedef olmaları nedeniyle mikotoksin açısından önemlidir. Tahıl olarak buğday, arpa, yulaf, çavdar, mısır ve pirinçte bulunabilecek başlıca mikotoksinler aflatoksinler, fumonisinler, trikotesenler (T-2 toksin, HT-2 toksin, nivalenol/NIV, deoksinivalenol / vomitoksin / DON, diasetoksirpenol / DAS gibi), OTA ve zearalenondur.

Aflatoksinler, Aspergillus flavus, Aspergillus parasiticus ve Aspergillus nomius gibi mantarların gida ve yemlerdeki toksik metabolitleridir. Bu mantarlar, bir çok tahıl ürününde yetiştirilme, hasat ve depolanma aşamalarında ortamın 1s1 ve nemine bağlı olarak yerleşip üremeye ve toksik metabolitleri olan aflatoksinleri üretmeye devam ederler. Yemlerdeki aflatoksinin en önemli kaynakları mısır, yerfıstığı küspesi ve pamuk tohumu küspesi gibi yem hammaddeleridir. $\mathrm{B}_{1}$, $B_{2}, G_{1}, G_{2}$ bu grubun en önemli toksinleridir ${ }^{3}$. Aflatoksinler, insanlar ve hayvanlarda başlica immun sistemi baskılayabilmekte ve özellikle karaciğerde kanser oluşumuna yol açabilmekte$\mathrm{dir}^{11}$. Aflatoksin kontrollerinde (findık ve antepfistığı dahil) AB'nin uyguladığı tolerans limitleri $\mathrm{AFB}_{1}$ için $2 \mathrm{ppb}(2 \mu \mathrm{g} / \mathrm{kg})$, toplam aflatoksin $\left(\mathrm{B}_{1}+\mathrm{B}_{2}+\mathrm{G}_{1}+\mathrm{G}_{2}\right)$ için $4 \mathrm{ppb}(4 \mu \mathrm{g} / \mathrm{kg})$ iken ${ }^{1}$, bu limitler Türk Gıda Kodeksi'ne göre sırasıyla 5 ve $10 \mathrm{ppb}^{\prime} \mathrm{dir}^{33}$.

Fumonisinler, trikotesenler ve zearalenon Fusarim türüne ait çeşitli mantarlar tarafından üretilir $^{6,31,32}$. Fumonisinler atlarda lökoensefalomalasi ${ }^{10,16}$, domuzlarda akciğer ödemi ${ }^{21}$, kanatlılarda düşük performans ve ölüme yol açabilmekte $^{27}$ ve ratlarda da hepatokarsinojenik etki oluşturabilmektedir ${ }^{12}$. Trikotesenler, sitotoksik ve sitostatik etkiye sahiptir. OTA, başlıca nefrotoksik etkiye sahiptir, ayrıca hepatotoksik ve embriyotoksik etkiye de neden olabilmektedir'. Zearalenon östrojenik etkili bir mikotoksindir. Yemlerdeki miktarına bağlı olarak, hayvanlarda östrus siklusunun bozulmasına, kalıcı korpus luteum ve serum progesteron düzeylerinin yüksek olarak devam etmesine yol açar. Zearalenon, farelerde uzun süreli maruziyette karsinojeniteye neden olabildiğinden Uluslararası Kanser Araştırma Merkezi zearalenonu karsinojen etkenler içinde 3. Grupta sınıflandırmıştır ${ }^{14}$.

\section{Süt ve ürünleri}

Süt ve ürünlerinde aflatoksin $\mathrm{M}_{1}\left(\mathrm{AFM}_{1}\right)$, $\mathrm{M}_{2}\left(\mathrm{AFM}_{2}\right)$ siklikla bulunabilen aflatoksinlerdir. Ayrica, sütte OTA ve siklopiazonik asit de (CPA) bulunabilmektedir ${ }^{25,35}$.

Aflatoksin $\mathrm{B}_{1}\left(\mathrm{AFB}_{1}\right)$, toksisitesi en fazla olan aflatoksindir ve $\mathrm{AFM}_{1}$ bunun sütle atılan metabolik ürünü, $\mathrm{AFM}_{2}$ ise aflatoksin $\mathrm{B}_{2}$ 'nin sütle atılan metabolik ürünüdür. $\mathrm{AFM}_{1}$ ve $\mathrm{AFM}_{2}$ laktasyondaki hayvanların $\mathrm{AFB}_{1}$ ve $\mathrm{AFB}_{2}$ içeren 
yemlerle beslenmesinden sonra sütle atıldığ 1 için süt ve peynir, yoğurt, süt tozu, tereyağ 1 gibi süt ürünlerinde bulunabilmektedir. Ancak $\mathrm{AFM}_{1}$ sütte en fazla bulunan ve dolayısıyla daha toksik olan aflatoksindir. $\mathrm{AFM}_{1}$ pastörizasyon, UHT gibi 1sı işlemlerine dayanıklıdır. Aflatoksinlerin başlica immunotoksik ve karsinojenik etkileri nedeniyle belirlenmiş tolerans limitleri bulunmaktadır. $\mathrm{Bu}$ tolerans limitleri Codex Alimentarius $^{7}$ için $500 \mathrm{ng} / \mathrm{kg}$, Avrupa Birliğ $\mathrm{i}^{8}$ ve Türkiye $^{33}$ için ise $50 \mathrm{ng} / \mathrm{kg}$ 'dır.

OTA, Penicillium verrucosum, Aspergillus ochraceus ve düşük oranlarda Aspergillus niger tarafindan üretilir. OTA, $30{ }^{\circ} \mathrm{C}$ altında ve $\% 80$ (0.80 su aktivitesi) nem bulunan iklimlerde daha fazla üretilir' ${ }^{9}$. Bu nedenle de daha çok serin iklime sahip bölgelerde (Kanada ve Avrupa gibi), tahıl ve ürünlerinde bu toksin daha yaygın görülür. OTA sindirim kanalından emildikten sonra daha çok böbreklerde bulunur, karaciğer, kas ve yağ dokusunda da daha düşük miktarlarda bulunur. Rat, tavşan ve insanlarda süte geçmekle birlikte, ruminantlarda rumen mikroflorasından dolayı düşük miktarlarda geçmektedir ${ }^{9,25}$.

CPA, bazı Aspergillus ve Penicillumlar tarafindan sentezlenen bir indol tetramik asit mikotoksindir. CPA, hayvanlarda katalepsi ve opistotonus gibi nörolojik semptomlara yol açar. Karaciğer, böbrek ve sindirim sistemi hedef organlarıdır ve 1960'l1 y1llarda İngiltere'de meydana gelen "Turkey ' $X$ ' hastalığı" aflatoksinle birlikte rol oynadığı belirtilmektedir. İnsanlar üzerindeki zararlı etkileri henüz tam olarak açığa çıkarılamamıştır, ancak uyuşukluk, tremor ve baş dönmesi yaptığı bildirilmiştir ${ }^{9,26}$. Yemde bulunan CPA süte geçmektedir. CPA'l1 sütün dondurulması ve pastörizasyon gibi işlemler CPA miktarında önemli bir azalma yapmaz ${ }^{25}$, ancak $120{ }^{\circ} \mathrm{C}$ 'de 30 dakika 1 s1 uygulandığında \%33-36 azalma meydana gelebilmektedir ${ }^{26}$. Bu nedenle CPA tüketicilerin sağlığ fazla risk oluşturabilecektir.

\section{Findık, Antepfistığı, Yerfıstığı ve İncir}

Türkiye, yaklaşı 600 bin ton kabuklu findık üretimiyle (1997-2001 yılları ortalaması) dünyada birinci sırada bulunmaktadır ${ }^{13}$. Findık kuruyemiş olarak tüketilen bir gıda maddesidir, findık küspesi de yem hammaddesi olarak kullanılabilmektedir. Findıkta bulunabilen en önemli mikotoksinler aflatoksinlerdir. Avrupa Birliği (AB) ülkelerine fındık ihracatında zaman zaman ciddi sorunlarla karşılaşılmaktadır. $\mathrm{Bu}$ nedenle
AB İspanya'ya daha sağlıklı findık yetiştirmesi için teşvik vermektedir. Aflatoksinlere hasattan önce findık üzerinde pek rastlanamamakta, ancak sert kabuğun zedelenmesi ve findik kurdu gibi zararlıların etkisiyle, özellikle harman ve kurutma aşamasında oluşmaya başlamaktadırlar ${ }^{13}$.

Antepfistığında da en fazla görülen ve sorun oluşturan mikotoksinler aflatoksinlerdir. Antepfistığı başlıca İran, ABD ve Türkiye'de, ikinci derecede de Suriye, İtalya ve Yunanistan'da yetiştirilmektedir. Antepfistığında aflatoksinlerin oluşumunun başlıca nedenleri arasında zamanında ve etkin kurutma yapılamaması, kabuktan iç kısım ayrilırken meyve içinin zarar görmesi gibi ürünün işlenmesi sırasındaki hatalar ile depolama sirasindaki hatalar gelmektedir ${ }^{1}$.

Yerfıstığ1 ülkemizde özellikle kuruyemiş olarak tüketilen bir gıda maddesidir, ancak yer fistığı küspesi yem hammadesi olarak da kullanılabilmektedir. Hasat aşamasında, özellikle kurutma ve depolama sırasında aflatoksinler oluşabilmekte ve tüketici sağlığını tehdit edebilecek düzeylere ulaşabilmektedir.

İncirdeki aflatoksin miktarları diğer meyveler ile karşılaştırıldığında daha yüksek değerlerde olabilmektedir. Aflatoksinle kontaminasyon ağaç üzerinde başlamakta ve kurutma sırasında önemli miktarda artış göstermektedir. İncirde ayrica okratoksin A ve fumonisinler de fazla bulunabilmektedir ${ }^{13}$. Bu nedenlerle uygun şartlarda kurutulamayan incir insan sağlığı açısından daha riskli olabilmektedir.

\section{Zeytin}

Zeytin, beslenme ve ekonomik açıdan oldukça önemli bir gıda maddesidir. Sofralık üretildiği gibi zeytinyağı olarak da değerlendirilmektedir. Zeytin ve ürünlerinde aflatoksinler ve sitrinin bulunabilmektedir. Sitrininin özellikle zeytinlerin olgunlaşması sırasında, uygun olmayan şartlarda havuzların yüzeyinde oluştuğu belirtilmektedir ${ }^{30}$. Sitrinin, nefrotoksik ve immunotoksik etkilere sahiptir.

\section{Kırmızı biber}

Kırmızı biberler de yüksek miktarlarda aflatoksin içerebilmektedir. Aflatoksinlerle kontaminasyon daha çok ürünün kurutulması aşamasında, yerle temas ederek kurutulmasıyla oluşmakta ve sonrasında depolama şartları nedeniyle aflatoksin miktarında artış olmaktadır. 


\section{Tanı Yöntemleri}

Mikotoksinlerin analizinde, ince tabaka kromatografisi (TLC), Yüksek basınçlı sıv1 kromatografisi (HPLC), Gaz kromatografisi/kütle spektrometresi (GC/MS), Enzim bağlanmış immunoabsorbant yöntemi (ELISA) ve enzim aktivitesine bağlı immunoteknik (Enzyme Multiplied Immunotechnique/EMIT) uzun zamandır kullanılmaktadır. Ancak bunların dışında Flouresans Polarization Immunoassay (FPIA) yöntemi de mikotoksinlerin ölçümünde deneme aşamasındadır ve kullanılabileceği yönünde olumlu sonuçlar alınmıştır ${ }^{4,5,19,28}$.

Kromatografi, çok az miktardaki ve kimyasal yapıları birbirine yakın kimyasal madde veya karıșımlarının fiziksel ve kimyasal özelliklerine göre ayrılmasında kullanılan teknikleri içerir. Kromatografide genel olarak bir sabit (stasyoner) faz, bir de hareketli (mobil) faz vardir.

TLC'de cam bir levha üzerine ince bir tabaka halinde ve homojen olarak yayılan sabit (katı) faz için genellikle silikajel, selüloz ve türevleri, nişasta, poliamid ve alüminyum oksit gibi organik ve inorganik maddeler kullanılır. Hareketli faz olarak aseton, metanol, hekzan gibi solventler kullanılır. Günümüzde mikotoksinlerin analizinde kullanılabilmekle birlikte, eskisi kadar kullanımı yaygın değildir.

HPLC'de (LC) hareketli faz siv1 (asetonitril, metanol, etanol, tetrahidrofuran, etil asetat, su gibi solventler) ve sabit faz çok küçük katı parçacıklardan (kolonun dolgu maddeleri olan silisyum dioksit, alüminyum oksit, gözenekli polimer ve iyon değiştirici reçineler gibi) oluşmaktadır. HPLC ile mikotoksin analizinde bilinmesi gereken en önemli faktörlerden biri, hangi mikotoksinin hangi dedektörle aranacağının bilinmesidir. Örneğin aflatoksinler $\left(\mathrm{AFM}_{1}\right.$ dahil), fumonisinler ve OTA analizlerinde fluoresans dedektör; trikotesenlerin analizinde UV veya DAD dedektörü kullanılmalıdır. Ayrıca mikotoksinler kütle dedektörü (MS/Mass Specrometer) ile de LC-MS veya LC-MS/MS sistemi şeklinde analizi yapılır ${ }^{18,29}$, ancak kütle dedektörleri diğer dedektörlerden daha pahalıdır. Aflatoksin, fumonisin, okratoksin analizinde temelde C-18 kolonları ve mikotoksinlerin ekstraksiyon aşamasinda toksinlerin daha konsantre ve saf olarak elde edilebilmesi için genellikle İmmüno Affinite Kolonları (IAK) kullanılmalıdır. HPLC mikotoksin analizlerinde en fazla kullanılan analiz yöntemlerinden biridir.
Gaz kromatografide (GC), hareketli faz hidrojen, azot ve helyum gibi gazlardan oluşur. Sabit faz sıvı veya katı olabilir ve çok küçük katı parçacıklardan (kolonun dolgu maddeleri olan silisyum dioksit, alüminyum oksit, gözenekli polimer ve iyon değiştirici reçineler gibi) oluşmaktadır. İki tür gaz kromatografi vardır: Gazkatı kromatografi (GSC) ve gaz-sivi kromatografi $(\mathrm{GLC})^{17}$. Gaz-sıv1 kromatografi daha fazla kullanım alanı bulmuş ve prensip olarak analitin gaz halindeki hareketli faz ile bir katının yüzeyine tutturulmuş durgun sıv1 faz arasında dağılımı üzerine kurulmuştur. Numune (analit) buharlaştırilır ve kromatografik kolonun girişine enjekte edilir. İnert bir hareketli gaz fazı ile elüsyon yapılır. Diğer kromatografik yöntemlerin aksine gaz faz analitin molekülleri ile etkileşmez; gazın tek işlevi, analiti kolon boyunca taşımaktır. Mikotoksinlerin analizinde GC'ye Mass Spectrometry (MS) dedektörü bağlanarak mikotoksinler atomlarına kadar parçalanabilmekte ve böylece ölçümleri yapılabilmektedir. Ancak mikotoksinlerin analizi GC/MS ile yapılabilmekle birlikte diğer sistemler daha pratik olduğundan GC/MS pek tercih edilmemektedir.

Günümüz yöntemlerden biri olan mikotoksin analizlerinde en sık kullanılan ELISA tekniğinde genellikle katı yüzeylere bağlanmış az miktarda antikor (antibadi) ile örneklerde bulunan toksin ve toksin ile işaretlenmiş enzimlerin bağlanma mücadelesini temel almaktadır. Yapılan yıkama sonrası bağlanmamış enzimler ayrılmakta, kullanılan belirli substrat ile meydana gelen renkli madde miktarı ile toksin miktarı ters orant111 olarak bulunan toksin miktarının hesaplanmas1n1 sağlamaktadır. EMIT'de siklosporin gibi (cyclosporine) gibi bazı toksinlerin analizinde kullanılabilmektedir ${ }^{4,5}$.

FPIA metodu son zamanlarda aflatoksin, deoksinivalenol, fumonisin ve zearalenon gibi bir çok mikotoksinin tayininde kullanılmaya başlamıştır. ELISA'dan temel farkı, yıkama basamaklarının ve amplifikasyon basamağının (enzimatik reaksiyon) kaldırılmasıdır. Bu nedenle uygulaması daha basittir ve daha kısa sürede analiz gerçekleştirilebilmektedir, ancak pratik olarak kullanımı için bir süre daha üzerinde çalışılması gereken bir teknik olarak görünmektedir ${ }^{5}$.

\section{Sonuç}

Mikotoksinler, gida ve yemlerde bulunan kimyasal etkenler içerisinde insan ve hayvan sağ- 
lığını tehdit eden en ciddi risk faktörlerinden biridir. Türkiye'nin bulunduğu coğrafya, pek çok mikotoksin üreten küflerin üremesi ve toksin üretmesi için uygun iklim şartlarına sahiptir. $\mathrm{Bu}$ nedenle mikotoksinlerin tarımsal ürünlerde oluşumunun önlenmesi, toksinin yem ve gıdalardaki varlığının doğru tespit edilmesi oldukça önemlidir. Ayrıca, tarımsal ürünlerin yetiştirilmesinden insan ve hayvan gıdası olarak tüketimine kadar olan tüm aşamalarda çalışmakta olan kişi ve kuruluşların mikotoksinler, insan ve hayvan sağlığ açısından önemi konusunda yeterince bilgilendirilmesi gerekmektedir. Türkiye'de bu konuda Avrupa Birliği ile ilişkiler ve ihracatta karşılaş1lan sorunlar nedeniyle önemli iyileştirmeler yapılmakta, kamu ve özel sektör kuruluşları mikotoksinler ve önemi konusunda daha etkin faaliyetlerde bulunmakta, bu da bilimsel veriler ve bu ürünlerin ihracat gelirlerine yansımaktadır.

Sonuç olarak, mikotoksin analizlerinin rutin olarak ve uygun yöntemlerle kontrolleri yap1lamadığ 1 taktirde, mikotoksinler insan ve hayvan sağlığını açısından bir risk oluşturmaya ve ihraç ürünlerinde karşılaşılan sorunlar nedeniyle büyük ekonomik kayılara neden olmaya devam edecektir.

\section{Kaynaklar}

1. ALUÇ M, ALUÇ S. Antep Fıstıklarında Aflatoksin Kirliliği. II. Ulusal Mikotoksin Sempozyumu Bildiri kitab1, sayfa 26-33, 23-24 Mayıs, 2005, İstanbul.

2. ANKLAM E, STROKA J. The European perspective of mycotoxins and food safety.In Int. Workshop on Mycotoxin. July, 22-26, 2002.. FDA and JIFSAN, University of Maryland, USA.

3. BENNETT JW, KLICH M. Mycotoxins. Clin.Microbiol.Rev. 2003; 16:479-516.

4. BONWICK GA, SMITH CJ. Immunoassays: their history, development and current place in food science and technology. Int. J. Food Sci. Tech. 2004;39:817-827.

5. BOZOĞLU F. Mikotoksin analiz yöntemlerindeki gelişmeler, floresans polarizasyon iminoesseyi (FPIA). II. Ulusal Mikotoksin Sempozyumu Bildiri kitabı, sayfa 26-33, 23-24 May1s, 2005, İstanbul.

6. CEYLAN S. Toksikoloji (Veteriner). Biyotoksinler, sayfa 68-77, U.U. Veteriner Fakültesi Yayınları, Bursa, 2003.

7. Codex Alimentarius. Maximum level for aflatoxin $\mathrm{M}_{1}$ in milk. Codex Stand. 232, 2001.
8. Commission of The European Communities. Commission regulation (EC) No.1525/98 of 16 July 1998 amending Regulation (EC) No.194/97 of 31 January 1997 setting maximum levels for certain contaminants in foodstuffs. Off. J. Europ. Com. 1998; 201:43-46.

9. CREPPY EE. Update of survey, regulation and toxic effects of myvotoxins in Europe (Review article). Toxicology Letters, 2002;127:19-28.

10. DEMIR C, ŞİMŞEK O, ARICI M. Samsun ve civarında yetiştirilen mısırlarda Fusarium miniliforme, fumonisin $\mathrm{B}_{1}$ ve fumonisin $\mathrm{B}_{2}$ varlığ üzerine bir araştırma. II. Ulusal Mikotoksin Sempozyumu Bildiri kitab1, sayfa 67-72, 23-24 May1s, 2005, İstanbul.

11. FINK-GREMMELS J. Mycotoxins: Their implications for human and animal health. Vet.Quart. 1999; 21 (4):115-120.

12. GOLDERBLOM WCA, LEBEPE-MAZUR S, SNIJMAN PW, ABEL S, SWANEVELDER S, KRIEK NPJ, MARASAS WOF. Toxicological effects in rats chronically fed low dietary levels of fumonisin $\mathrm{B}_{1}$. Toxicology 2001; 161:39-51.

13. HEPERKAN D. Mikotoksinleri önemi ve Türkiye'deki mikotoksin çalışmaları. II. Ulusal Mikotoksin Sempozyumu Bildiri kitabı, sayfa 311, 23-24 May1s, 2005, İstanbul.

14. IARC. Overall evaluations of carcinojenicity to humans. IARC monographs, 1999;1-73:1-36.

15. JORGENSEN K, PETERSEN A. Content of ochratoxin A in paired kidney and meat samples from healthy Danish slaughter pigs. Food Add. 2002;19 (6):562-567.

16. KELLERMAN TS, MARASAS WFO, THIEL PG, GELDERBLOM WCA, CAWOOD M, COETZER JA. Leukoencephalomalasia in two horses induced by oral dosing of fumonisin $\mathrm{B}_{1}$. Onderstepoort J.Vet. Res. 1990; 57:296-275.

17. KILIÇ E, KÖSEOĞLU F, YILMAZ H, (Çeviri Edit.). Enstrümantal Analiz, Gaz Kromatofrafi, Bölüm 27, II. Baskı, Bilim Yayıncılık, Ankara, 1998.

18. LAUNAY FM, YOUNG PB, STERK SS, BLOKLAND MH, KENNEDY DG. Confirmatory assay for zeranol, taleranol and the Fusarium spp. toxins in bovine urine using liquid chromatography-tandem mass spectrometry. Food Addit. Contam. 2004;21(1):52-62.

19. NASIR MS, JOLLEY ME. Fluorescence Polarization (FP) Assays for the Determination of Grain Mycotoxins (Fumonisins, DON Vomitoxin and Aflatoxins). Comb. Chem. Hight T. Scr. 2003;6:267-273.

20. NJAPAU H, PARK DL. Aflotoxicosis outbreak in Kenya: Lessons learned. II. Ulusal Mikotoksin 
Sempozyumu Bildiri kitabı, sayfa 12, 23-24 Mayıs, 2005, İstanbul.

21. OSWEILER GD, ROSS PF, WILSON TM, NELSON PE, WITTE ST, CARSON TL, RICE LG, NELSON HA. Characterization of an epizootic of pulmonary edema in swine associated with fumonisin in corn screenings. J. Vet. Diag. Inves. 1992; 4:53-59.

22. PARK D. Mycotoxin control-regulations. In Int. Workshop on Mycotoxin. July, 22-26, 2002. FDA and JIFSAN, University of Maryland, USA.

23. PFOHL-LESZKOWICZ A, PETKOVABOCHAROVA T, CHERNOZEMSKY IN, CASTEGNARO M. Balkan endemic nephropaty and associated urinary tract tumors: a review on aetiological causes and potential role of mycotoxins, Food Addit. Contam. 2002; 19:282302.

24. PITT JL. Biology and ecology of toxigenic Penicillium species, in: Mycotoxins and Food Safety. pp 29-41. J.W.Devries, M.W.Trucksess, and L.S.Jacson., eds. Kluwer Academic/Plenum Publishers, New York, 2002.

25. PRASONGSIDH BC, KAILASAPATHY K, SKURRAY GR, BRYDEN WL. Stability of cyclopiazonic acid during storage and processing of milk. Food Res. Int.1997;30(10):793-798.

26. PRASONGSIDH BC, KAILASAPATHY K, SKURRAY GR, BRYDEN WL. Kinetic study of cyclopiazonic acid during the heat-processing of milk. Food Chemistry. 1998;62(4):467-472.

27. PRATHAPKUMPAR SH, RAO VS, PARAMKISHAN RJ, BHAT RV. Disease outbreak in laying hens arising from the consuption of fumonisin-contaminated food. Br. Poult. Sci. 1997; 38(5):475-479.
28. SHIM WB, KOLOSOWA AY, KIM YJ, YANG ZY, PARK SJ, EREMIN SA, LEE IS, CHUNG DH. Fluorescence polarization immunoassay based on a monoclonal antibody for the detection of ochratoxin A. Int. J. Food Sci. Tech. 2004;39:829837.

29. SORENSEN LK, ELBAEK TH. Determination of mycotoxins in bovine milk by liquid chromatography tandem mass spectrometry. J. Chromatogr. B 2005;820:183-196.

30. ŞAHİN İ, BAŞOĞLU F, KORUKLUOĞLU M, GÖÇMEN D. Salamura siyah zeytinlerde rastlanan küfler ve mikotoksin riskleri. Kükem Dergisi, 1999;22(2):1-8.

31. ŞANLI Y, KAYA S, PİRINÇCI İ, YAVUZ $\mathrm{H}$, BAYDAN E, DEMET Ö, BİLGILİ A. Veteriner Klinik Toksikoloji, Mikotoksinler, sayfa 283-328, Medisan Yayınevi, Ankara, 1995.

32. ŞENER S, YILDIRIM M. Toksikoloji (Veteriner). Mikotoksinler, sayfa 239-273, Teknik Yayıncilık, İstanbul, 2000.

33. Türk Gıda Kodeksi. Gıda Maddelerinde Belirli Bulaşanların Maksimum Seviyelerinin Belirlenmesi Hakkında Tebliğ, Tebliğ No: 2002/63, Ek-1 Mikrobiyal Toksinler, 2002.

34. VRABCHEVA T, USLEBER E, DIETRICH R, MARTLAUBER E. Co-occurence of ochratoxin A and citrinin in cereals from Bulgarian villages with a history of Balkan endemic nephropathy. J. Agric. Food Chem. 2000;48:2483-2488.

35. WHO/FAO. WHO Food Additives Series: 47. FAO Food and Nutrition Paper. Safety evaluation of certain mycotoxins in food. Ochratoxin A. 281680, Geneva, 2001. 